\title{
Co-Amorphous System: A promising Strategy for Delivering Poorly Water - Soluble Drugs Iman S. Jaafar ${ }^{*}, 1$ and Ameera A. Radhi*
}

${ }^{*}$ Department of Pharmaceutics, College of Pharmacy, University of Mustansiryah, Baghdad, Iraq

\begin{abstract}
Amorphization of drug has been considered as an attractive approach in improving drug solubility and bioavailability. Unlike their crystalline counterparts, amorphous materials lack the long-range order of molecular packing and present the highest energy state of a solid material. Co-amorphous system (CAM) is a multicomponent single phase system containing an active pharmaceutical ingredient (API) with a low molecular weight excipient or a pharmacologically relevant API. This review highlights the different approaches followed in the preparation of co-amorphous drug delivery system, and the proper selection of the co-formers. In addition, the recent advances in solid state characterization, industrial scale and formulation will be discussed.
\end{abstract}

Keywords: Co-amorphous ,Co-former, Preparation, Characterization.

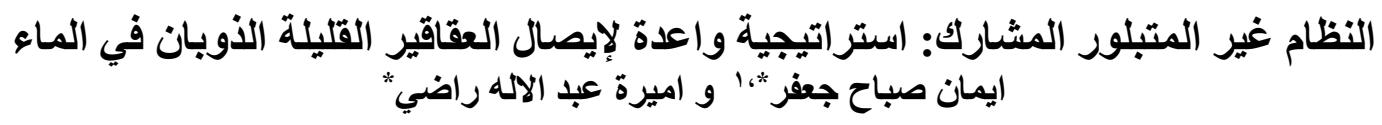

*فرع الصيدلانيات، كلية الصيدلة، الجامعة المستتصرية، بغداد ، العراق.

الخلاصة

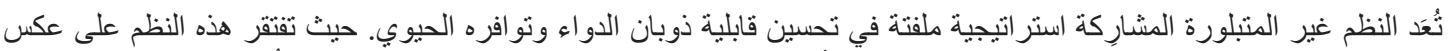

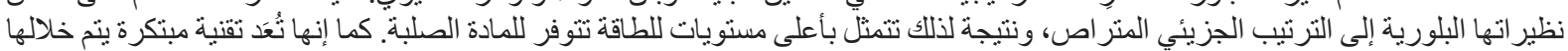
تأمين استقر ار العقار في الحالة الغير المتبلورة ومنع تبلوره بو اسطة او اصر بينية مع جزيئات لمركبات منخفضة الوزن الجزيئي(الثريك الجزئئي)

تسلط مر اجعة المقال الضوء على الطرق المختلفة في إعداد نظام توصيل الأدوية غير المتبلور، واختيار الشريك الجزيئي الأمثل. اضافة

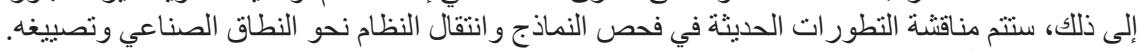
الكلمات المفتاحية: النظام غير المتبلور المشارتى، شريك جزيئي ، تحضير ، تشخيص.

\section{Introduction}

A growing number of new active pharmaceutical ingredients (APIs) have been revealed as a result of high-throughput screening technology progress ${ }^{(1,2)}$.

The most widespread challenge is their low water solubility. In the biopharmaceutics classification system (BCS), these drugs are off the record as class II and class VI, respectively ${ }^{(3)}$.The low water solubility of such drugs will decrease the drug bioavailability seriously and may prevent further development of new chemical entities if it remains without satisfactory solution ${ }^{(4)}$. For this reason, different methods have been adopted such as salt formation, cyclodextrin inclusion, solid dispersions, nanocrystals, microemulsion, cocrystals and amorphous dispersions; etc. ${ }^{(5,6)}$. Along with these strategies, one of the most effective approaches to improve the solubility and dissolution of poorly water-soluble drugs is the amorphization ${ }^{(7)}$. Amorphous materials lack the uniform molecular packing typical for crystalline solids and present the highest energy state of a solid material ${ }^{(8)}$. The improvement in the apparent solubility and dissolution profile in amorphous materials might be attributed to the low energy barrier necessary for molecules to go into solution Yet, the amorphous systems potential application is limited, owing to thermodynamic instability causing recrystallization throughout processing, when they get in contact with the fluids of biological system or during storage ${ }^{(9)}$. Consequently, the stabilization of amorphous API using various formulation strategies has been investigated ${ }^{(10)}$.

\section{Definition of co-amorphous system (CAM)}

Co-amorphous system (CAM) is a multicomponent single phase system containing an active pharmaceutical ingredient (API) with either a low molecular weight excipient or a pharmacologically relevant API ${ }^{(11,12)}$.

${ }^{1}$ Corresponding author E-mail: emanaldahan@gmail.com

Received: 24/5/2019

Accepted: 29/ 9/2019

Iraqi Journal of Pharmaceutical Science 
The application of small molecules like urea, citric acid, tartaric acid to stabilize amorphous forms has been reported earlier in the literature ${ }^{(13,14)}$. The term "co- amorphous" was introduced in 2009 by Chieng et al. in attempt to distinguish the amorphous mixture containing two small molecules from the term polymeric amorphous solid dispersion (PASD) (15). The first drug-drug CAM was developed by combining naproxen with cimetidine, by Yamamura et al. The solubility and dissolution rate enhancement were attributed to amorphous form stabilization of both drugs throughout intermolecular hydrogen bonding ${ }^{(16)}$.

Advantages and limitations of co-amorphous system (CAM)

Co-amorphous systems afford high degree of solubility due to higher amorphous energy state. Furthermore, no energy is required for the rearrangement of the crystal lattice during dissolution ${ }^{(17,18)}$. In addition, they may show high degree of stability as compared to the amorphous form entity and dissolution rate enhancement in comparison to their crystalline homologues (19-21). The stability of CAM is mainly caused by an increase of glass transition temperature $(\mathrm{Tg})$ and the homogenous molecular-level dispersions achieved by high energy mixing (22). Attributable to the components with low MW, the required quantity of the stabilizer (co-former) is low and thus overcoming the large bulk volume of the final dosage forms associated with PASD ${ }^{(23)}$.

A remarkable increase in peak concentration (Cmax) and area under curve (AUC), in addition to a decrease in peak time (Tmax) has been observed in many CAM mixtures ${ }^{(24,22)}$.

Being an amorphous system, CAM is inherently susceptible to nucleation and crystal growth leading to the recrystallization to the more stable form. Therefore, it is not possible to ensure the complete stability in the final dosage form ${ }^{(25,26)}$.

The main challenges CAM mixtures may encounter during formulation are their sensitivity to heat and moisture ${ }^{(27)}$. To date, few studies have investigated the impact of different temperature and humidity conditions on the CAM stability ${ }^{(28)}$. Other hurdles might be attributed to their limited compressibility and flowability. The compression pressure might compromise the interactions between the drug and stabilizer molecule which in turn causes crystallization and negatively influences the physical stability as well as the dissolution performance of co- amorphous system in the last dosage form ${ }^{(29)}$.

\section{Classification of CAM}

Based on the low molecular weight partner, CAM can be classified into drug-drug CAM and drug- excipient CAM. Until now, approximately fifty different drug-drug and drug-excipient CAM have been investigated ${ }^{(30)}$.

\section{Drug-drug CAM}

In this system, stabilization of two drugs which are pharmacologically- related is obtained, as one drug functions as amorphous stabilizer for the other drug. In addition to the benefits of improved solubility, dissolution and stabilization, this system provides a platform for the innovative combinational therapy ${ }^{(31)}$. More efficient therapy is attained from the combination of two different therapeutic categories drugs ${ }^{(32)}$. Furthermore, the concurrent one dosage unit administration of the drugs results in least excipients as well as improved patient compliance. Usually CAM are formed in molar ratio of 1:1, which may demonstrate stability enhancement as it implicates that both CAM components network at molecular level via hydrogen bonds ${ }^{(13,21)}$. The CAM approach may also offer improvement of bioavailability, since one of the drugs can work as a dissolution-enhancing agent, in addition to amorphous-stabilizing agent for the second drug ${ }^{(33,34)}$. Great enhancement in the hydrochlorothiazide - atenolol co-amorphous mixture in bioavailability as compared to that of the physical mixture, (drug in amorphous form and crystalline drug) ${ }^{(11)}$.

The earliest drug-drug CAM was reported by Yamamura et al., in 1996. Binary mixtures of cimetidine with naproxen ${ }^{(16)}$, indomethacin ${ }^{(35)}$ and diflunisal (36) were prepared using solvent evaporation method. Another example of investigated drug- drug CAM is indomethacin with ranitidine hydrochloride CAM for treatment of the pain and the prevention of NSAIDs gastrointestinal adverse effects ${ }^{(15)}$, simvastatin with glipizide for lipid disorders and diabetes mellitus in metabolic disease $^{(37)}$ and tranilast (antiallergic) with diphenhydramine hydrochloride for management of allergy and inflammation ${ }^{(38)}$.

The investigated drug-drug combinations are generally still low, because of the limited number of pharmacologically- relevant drug pairs that can form glass solution in the required therapeutic dose ${ }^{(29)}$. Consequently, the idea of drugs combinations with inert molecules that can form hydrogen bonding and have low toxicity are more applicable ${ }^{(39,40)}$.

\section{Drug- excipient CAM}

In these systems, drugs with poor solubility were combined with inactive excipients of lowmolecular-weight. These excipients contain weak carboxylic acids, like tartaric acid ${ }^{(41)}$ and citric acid ${ }^{(42)}$, weak bases, like saccharin ${ }^{(39)}$, meglumine (amino sugar) (43), phospholipids (44), sugars, nicotinamide and urea ${ }^{(45)}$.

The mechanism of stabilization of these CAM was credited to direct molecular interactions for instances; hydrogen bonding, charge assisted interactions, molecular level mixing and if possible, an increase of the drug $\mathrm{Tg}{ }^{(46)}$.

Besides, the amorphous stabilization, an increase in skin permeation was observed with acyclovir and 
citric acid CAM compared to crystalline acyclovir (47). Additionally, high physical stability even at storage conditions above the $\mathrm{Tg}$ of the mixture was obtained in paracetamol and citric acid CAM as a result of the strong intermolecular interactions ${ }^{(48)}$.

Biocompatible co-formers, amino acids, were also used as anti-plasticizers by raising the $\mathrm{Tg}$, inhibiting drug-drug interactions and holding up recrystallization. Amino acids were chosen based on the knowledge of probable drug-receptor interactions at the biological binding sites ${ }^{(49,50)}$.

Both dissolution rate improvement and physical stability of drug co-amorphous -amino acids systems in comparison to the drug in amorphous state have been achieved, owing to molecular interaction $^{(12,20,49,50)}$. Though, systems stability by non-interacting components is also a potential ${ }^{(20)}$.

Amino acids - salts formation showed higher mixtures stability ${ }^{(51)}$. Salts act as anti-plasticizers and increases the Tg of CAM mixture. This effect is mainly due to the powerful ionic interactions that oppose crystals formation ${ }^{(17)}$. Moreover, formation of salts enhanced dissolution, as a result of iondipole interactions between the dissolved ions and the water molecules. This type of interaction is energetically preferred over hydrogen bonding between non-ionized drugs with water molecules (34).

\section{Methods for co- amorphous formulations preparation}

An acceptable performance of the final dosage form depends mainly on choosing the proper approach to prepare CAM formulations. In general, the selection of preparation procedure is influenced by the properties of active ingredients as well as the excipients. Additionally, significant differences in physical stability in addition to dissolution performance of co-amorphous formulations result from different preparation methods ${ }^{(29)}$.

Different techniques of preparation of CAM are available, and they include mechanical activation (milling), solvent (solvent evaporation, spray drying and freeze drying) and techniques involving melting (52).

\section{Milling methods}

This method is the most commonly applied methods to prepare stable CAM owing to simplicity of handling, and minimum chemical degradation (if the processing occurs at low temperature), in addition to the high yield in comparison to other techniques ${ }^{(53)}$.

According to the molecular packing point of view, introduction of enough mechanical stress to produce crystal defects leads to loss of long-range crystallographic periodicity of crystalline materials $(54,55)$.

The raised temperature, during conventional ball milling, eventually leads to recrystallization. Therefore, conducting milling at low temperatures essentially avoids fast re-crystallization and is considered an effective approach for producing CAM dispersions. This result provides foundation of cryo-milling for low Tg drugs where the temperature of the process is lowered down using liquid nitrogen ${ }^{(56)}$.Most pharmaceuticals turn fragile at the cryogenic temperature (temperature much lower than $\mathrm{Tg}$ ), favoring formation of the disordered form upon mechanical activation. Additionally, the risk of degradation induced by heat along with recrystallization can be avoided through cryomilling. Cryo-milling is, therefore, considered more successful than conventional milling for production of $\mathrm{CAM}^{(57,58)}$.

One of crucial points which should be considered is that the milling technique can occasionally form highly defective crystals rather than the actual amorphous solids. The formed crystals can encourage nuclei formation and the growth of crystal in amorphous solids ${ }^{(59,60)}$.

\section{Solvent evaporation}

CAM is commonly prepared by this method, in which an ordinary organic solvent is used to dissolve crystalline drugs or excipients, then the solvent is evaporated by means of heat or under vacuum for not less than 24 hours. Any remaining solvent may lead to CAM instability through recrystallization or solvate formation during storage ${ }^{(61)}$.The solubility of both drug substance as well as excipient in the chosen solvent is of great significance to the size of the particles, physical consistency, in addition; to better dissolution performance of CAM prepared by this method ${ }^{(62)}$.

Due to solvent fast elimination, there is no chance of molecules to reorganize themselves in a crystal lattice. In addition, they are solubilized in the CAM by co-precipitation ${ }^{(15)}$.

Improved physical stability, enhanced $\mathrm{pH}$ independent solubility, superior intrinsic dissolution rate (IDR) as well as supersaturated dissolution were observed for lurasidone $\mathrm{HCl}$-saccharin CAM prepared by rotary vacuum evaporator compared to amorphous lurasidone $\mathrm{HCl}^{(63)}$.

The process of spray drying is generally divided into two steps: atomization step and drying step. The first step essentially involves spraying of an appropriate solution of APIs to a heated chamber with a control on the size of droplet as well as the rate of spraying. The last step necessitates the removal of the solvent out of droplets to yield dry particles. The particle size distributions and morphologies could be monitored via controlling the composition of the spray solution, and the rates of drying during the process ${ }^{(63)}$. Spray drying is a well-established technique and easily scalable process. However, this method has limitation which includes complexity in choosing the appropriate solvent for both drugs and excipients. Additionally; recrystallization may occur as a result of residual solvents. Furthermore, the use of organic solvents may cause safety 
concerns throughout the production and danger the environment ${ }^{(64,65)}$. Spray drying method provides an excellent choice to prepare CAM, but as other methods may be unsuccessful because of degradation by heat, low yield, and incomplete amorphization $^{(34)}$.

Freeze drying, which is also known as lyophilization, is employed to obtain products with porous and low-density nature. High-dose zwitterionic compound ofloxacin-amino acid CAM was prepared successfully by Zhu et al. through lyophilization ${ }^{(66)}$.

\section{Melt-quenching}

The melt quenching is a well-recognized technique employed in the fabrication of thermostable active ingredients in small quantities. This method involves intensive mixing APIs and/or excipients by heating to a molten liquid. Then, the melt is hastily cooled to a temperature under the melting temperatures of the individual components in order to prevent crystallization. Prevention of nucleation and growth of crystal is achieved by fast cooling rate, which consequently facilitate CAM formation. A stable CAM of citric acid-paracetamol preparation was reported by Hoppu et al. via meltquenching method ${ }^{(67)}$. It has been confirmed that CAM prepared by melt-quenching may show improved physical stability compared to those prepared by conventional ball milling, or cryomilling ${ }^{(68)}$. This is attributed to incomplete removal of small amount of residual crystals that encourage the crystallization ${ }^{(69)}$.

\section{Co-former selection}

Many low molecular weight molecules have been considered as potential co- formers in the formulation of CAM . Therefore, a successful design of CAM requires a close observation of the properties for both the co-formers and the active ingredient, for instance the glass transition
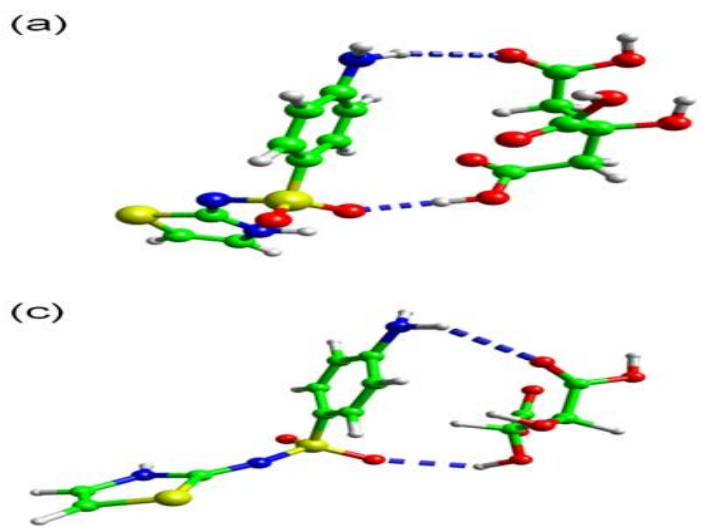

temperature ( $\mathrm{Tg}$ ), ability to form hydrogen bonding and their miscibility to form a homogenous mixture (70).

In order to ensure a maintained physical stability of the dispersion, the $\mathrm{Tg}$ of the mixture is favored about $50 \mathrm{~K}$ above the storage temperature $(\mathrm{Tg}-\mathrm{T} \sim 50 \mathrm{~K})$. Therefore, employing co-formers with relatively high value of $\mathrm{Tg}$ would increase the chance that the $\mathrm{Tg}$ of the mixture will be higher, especially when API exhibits a low Tg. The Tg of the mixture can be anticipated by Fox or Gordon-Taylor equations (71, 72).

$$
T_{g \text { mix }}=\frac{\mathrm{w}_{1} \mathrm{~T}_{\mathrm{g}_{1}}+\mathrm{k} \mathrm{w}_{2} \mathrm{~T}_{\mathrm{g} 2}}{\mathrm{w}_{1}+\mathrm{k} \mathrm{w}_{2}}
$$

where $T_{g \text { mix }}$ is $\mathrm{Tg}$ of the amorphous mixture, $\mathrm{T}_{\mathrm{g} 1}$ and $\mathrm{T}_{\mathrm{g} 2}$ are the glass transition temperature of each component, $\mathrm{w}_{1}$ and $\mathrm{w}_{2}$ are the weight fraction of each component, $K$ is a constant $, \rho_{1}, \rho_{2}$ are the densities of each component and $\Delta \alpha 1, \Delta \alpha 2$ represent the change in thermal expansivity of $\mathrm{Tg}$ of each component ${ }^{(73)}$ :

$$
\mathrm{K}=\frac{(\rho 1 \Delta \alpha 2)}{(\rho 2 \Delta \alpha 1)} \quad(2)^{(73)}
$$

The detection of hydrogen bond ability between co-amorphous components has extended to the use of computational and theoretical approaches such as, natural bond orbital analysis (NBO), density functional theory calculations (DFT) as well as quantum molecular theory (QTAIM) ${ }^{(74,75)}$.

Modeling the interaction between sulfathiazole and citric acid / tartaric acid was carried out using a molecular modeling functionality, Moilin, within Oscail which is a windows software for molecular modeling and crystallography. As shown in figure (1), due to the presence of three carbons between its - $\mathrm{COOH}$ groups, citric acid, was better able to span the sulfathiazole molecules than tartaric acid ${ }^{(41)}$.

(b)

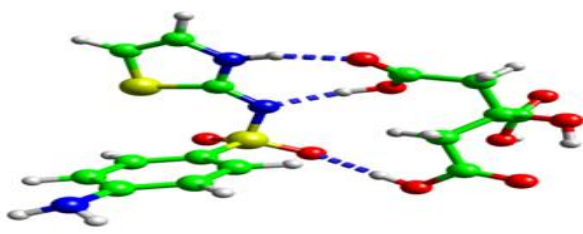

(d)

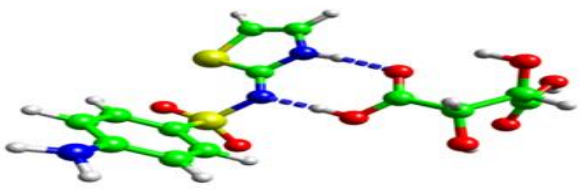

Figure 1. Calculated adduct structures for STZ-CA (a) and (b) and STZ-TA (c) and (d) ${ }^{(43)}$.

Flory-Huggins interaction parameter $(x)$ has been used to indicate the miscibility between small molecules in binary mixtures and estimate their phase stability. It has been reported that miscible systems would have a value of Flory-Huggins parameters $(x)$ close to or less than zero ${ }^{(76,77)}$.

This parameter was calculated for simvastatin and glipizide dispersion and the obtained value for $\chi$ was found to be $5.5 \pm 2.0$, which suggests the absence of 
molecular interactions between these components and thereby immiscibility ${ }^{(39)}$

\section{Solid state characterization of CAM}

X-ray powder diffraction (XRPD), Fouriertransform infrared spectroscopy (FTIR), in addition to differential scanning calorimetry (DSC) are commonly employed techniques to confirm both the formation and the stability of CAM ${ }^{(78,79)}$.

$\mathrm{X}$-ray powder diffraction (XRPD) is a wellestablished method that comes up with information on the existence of a crystalline material through the presence of sharp diffraction peaks, whereas amorphous material is recognized by a halo pattern in the PXRD ${ }^{(80)}$. Figure 2 demonstrates the diffractogram of docetaxel with characteristic diffraction peaks of crystalline docetaxel (2 a) in contrast to the halo pattern exhibited by docetaxel and myricetin system prepared by fast solvent evaporation technique $(2 \mathrm{e})^{(81)}$.

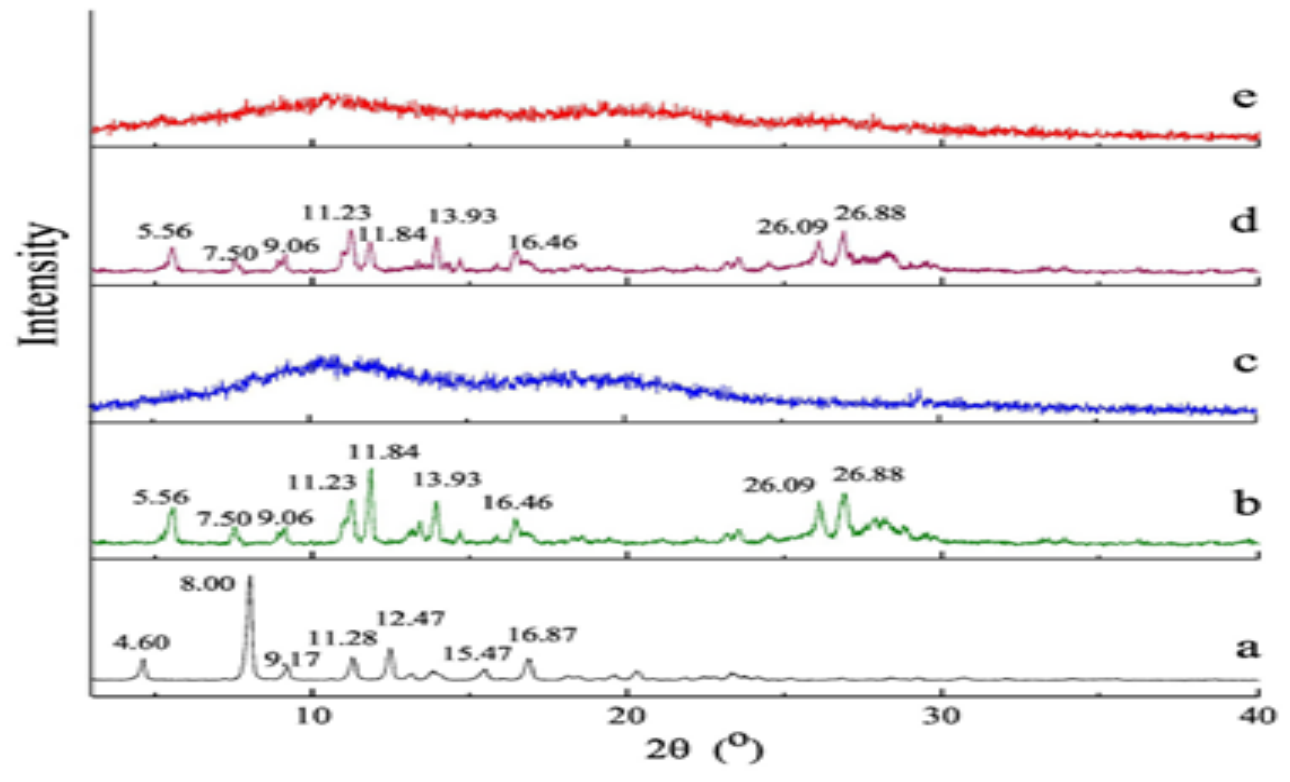

Figure 2. PXRD patterns of (a) crystalline docetaxel, (b) crystalline myricetin, (c) amorphous docetaxel, (d) rotary evaporation product of myricetin, and (e) co-amorphous docetaxel- myricetin ${ }^{\left({ }^{8}\right)}$

A successful CAM is identified in the DSC thermogram through a solitary $\mathrm{Tg}$ that corresponds to the transfer of glass status to a sub cooled or viscous fluid ${ }^{(82)}$. The presence of one $\mathrm{Tg}$ implies formation of a single-phase homogeneous systems $(83,84)$.

The problem of phase separation between the individual components of the mixture could be detected by the observation of two Tg values instead of a single $\mathrm{Tg}{ }^{\left({ }^{85)}\right.}$. Wang et al. prepared coamorphous loratadine-citric acid system in different molar ratios (1:1, 2:1 and 3:1). DSC thermograms revealed a single $\mathrm{Tg}$ for co-amorphous loratadinecitric acid system (1:1) which confirmed the homogenous phase formation. On the other hand, the appearance of two $\mathrm{Tg}$ values for formulations $(2: 1)$ and (3:1) suggested the formation of two phase mixture of loratadine-citric acid system and amorphous loratadine ${ }^{(86)}$.

The $\mathrm{Tg}$ of the mixture could be theoretically calculated using the Gordon-Taylor equation which suggests a state of ideal miscibility and absence of interactions between the components. It usually appears in a range between the $\mathrm{Tg}$ of the two individual components (87). However, the appearance of higher values of $\mathrm{Tg}$ in the DSC thermogram strongly suggests the presence of strong ionic forces due to salt formation between the drug and the co- former ${ }^{\left({ }^{8}\right)}$. On the other hand, lower values may occur due to the plasticizing effect of water residues or the loss of bonds during mixing ( ${ }^{89,}$ 90).

Alleso et al. studied the thermal events in the comilled binary mixture of naproxen and cimetidine. The experimental values of $\mathrm{Tg}$ (table 1) of the binary mixture at various molar ratios exhibited a significant deviation from those calculated by Gordon-Taylor equation. These results have been attributed to the strong solid-state interaction between the two molecules that has been successfully confirmed via Raman spectroscopy ${ }^{(18)}$. 
Table 1. Glass transition temperatures of mixtures and single components determined by DSC and calculated values using the GordonTaylor equation ${ }^{(18)}$

\begin{tabular}{||l|l|l||}
\hline Sample & $\begin{array}{l}\mathbf{T g}\left({ }^{\circ} \mathbf{C}\right) \\
\text { Experimenta } \\
\mathbf{l}\end{array}$ & $\begin{array}{l}\mathbf{T g ~}\left({ }^{\circ} \mathbf{C}\right) \\
\text { Calculate } \\
\text { d }\end{array}$ \\
\hline $\begin{array}{l}\text { Naproxen(NAP } \\
)\end{array}$ & $6.2 \pm 0.6$ & N/A \\
\hline $\begin{array}{l}\text { Cimetidine } \\
(\text { CIM)(milled) }\end{array}$ & $36.1 \pm 2.0$ & N/A \\
\hline 1:2 NAP-CIM & $42.2 \pm 1.1$ & 14.0 \\
\hline 1:1 NAP-CIM & $34.5 \pm 0.3$ & 10.7 \\
\hline 2:1 NAP-CIM & $31.5 \pm 0.7$ & 8.6 \\
\hline
\end{tabular}

The molecular interactions can be analyzed using Fourier-transform infrared spectroscopy (FTIR) ${ }^{(91)}$, Raman spectroscopy (92) and nuclear magnetic resonance (NMR) ${ }^{(93)}$.

The infrared spectral analysis of ketoconazolesuccinic acid mixture demonstrated a band at 1605 $\mathrm{cm}^{-1}$, therefore suggesting hydrogen-bonding interactions between ketoconazole and succinic acid as given in figure $3^{\left({ }^{(9)}\right.}$.

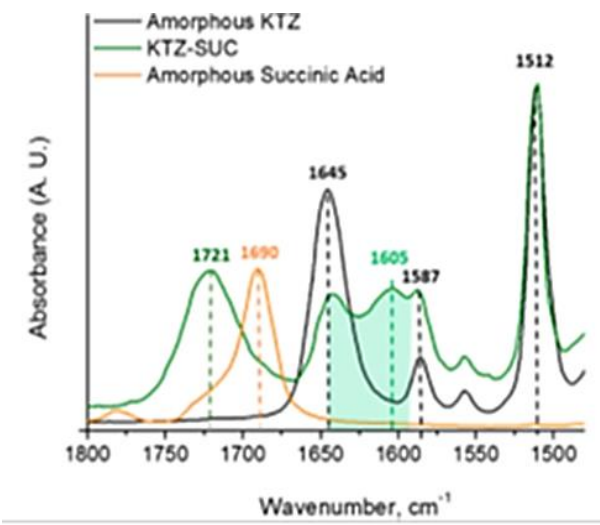

Figure 3. IR spectra of (a) amorphous KTZ, coamorphous KTZ-SUC, amorphous succinic acid ${ }^{(94)}$

Edinger et al. employed the transmission Raman spectroscopy to quantify the amorphization fraction of celecoxib in polyvinylpyrrolidone (PVP) tablet. The transmission Raman spectroscopy provided a fast at-line and non-destructive measurements after each microwaving step. The spectrum of amorphous celecoxib shows bathochromic shift of the in-plane bending of the phenyl ring, assigned at $810 \mathrm{~cm}^{-1}$, to $798 \mathrm{~cm}^{-1}$ and a merge with another peak centered at $794 \mathrm{~cm}^{-1}$ as well ${ }^{(95)}$.

Binary mixtures of indomethacin with tryptophan (Ind-Trp) and furosemide with tryptophan (Fur-Trp) prepared by ball milling were analyzed employing XRPD, ${ }^{13} \mathrm{C}$ solid status NMR (ssNMR), in addition to DSC. Based on data obtained from ${ }^{1 r} \mathrm{C}$
ssNMR spectra, it has been proposed that hydrogen bonding and $\pi$-interactions were responsible for amorphization in both systems ${ }^{(93)}$.

\section{Industrial scale}

The conversion of CAM into marketed pharmaceutical dosage forms requires selection of the preparation technique depending on the physicochemical properties of drug in addition to the co-former, primarily the melting point as well as thermal stability of the CAM components ${ }^{(96)}$.

As discussed previously, melt-quenching has been used for assessment purposes. However, the scalability of this method might be a challenging task due to the potential risks of in-process degradation and uneven mixing of the final product (97).

Hot-melt extrusion (HME), on the other hand, has been employed as the main preparation technique in several PASD based marketed pharmaceutical products and thus is considered as a promising method to scale up CAM ${ }^{(98)}$.

Moving to industrial scale for ball milling approach has been associated with several limitations. These limitations include, the heat produced during milling which makes this procedure applicable only to the thermostable drugs and high Tg excipients. The low yield from sticking of the product to the chamber due to the charge generated during the process, and the crystallization tendency induced by milling stress ${ }^{(99,100)}$

Spray drying is a convenient process that used in manufacture of solid dispersions ${ }^{(101)}$. It is, therefore, recognized as a promising method to scale up and manufacture of CAM ${ }^{(102)}$. For this reason, Jensen $e t$ al. investigated spray drying for production of indomethacin- basic amino acids mixture in comparison with vibrational ball milling. It was concluded that spray drying had provided a completed amorphization of the final product and thus a stable formulation for industrial manufacture (53).

\section{Formulation}

CAM can be administered orally via further formulation into tablets or capsules. However, commercial manufacture may encounter some difficulties due to their sensitivity to humidity and temperature. Wet granulation should be avoided in CAM formulation, since water might cause plasticization and crystallization. Similarly, the heating step during melt granulation can raise the temperature above the co-amorphous components $\mathrm{Tg}$ and might lead to recrystallization ${ }^{(103)}$.

The most prominent goal in the formulation of coamorphous dispersions is the protection from moisture. This could be achieved through blending with excipients that decrease the moisture uptake such as fumed silica. In addition, blister packaging under Argon atmosphere or the implication of some 
advanced materials such as high barrier thermoformable films, desiccant papers, cold formable foils provided with color changing cards as a reference to moisture levels ${ }^{(97)}$.

The first research to report a successful formulation of CAM tablets was conducted by Lenz et al., who formulated tablets containing spray dried indomethacin-arginine. The excipients used in this study were mannitol, croscarmellose sodium, colloidal silicon dioxide, magnesium stearate. Tablets were evaluated with respect to the influence of compaction pressure on the tablet properties, physical stability and dissolution profile. Data obtained from XRPD clearly revealed the absence of possible compression-induced crystallization during tableting and attainment of physical stability of the amorphous form in tablets during long term storage. Although indomethacin from the prepared tablet exhibited lower supersaturation than spray dried powder behavior, the area under curve (AUC) of dissolution profile of CAM was not affected by formulation of spray dried indomethacin-arginine into tablets ${ }^{(22)}$.

Polymeric coating using (Kollicoat ${ }^{\circledR}$ Protect) which is polyvinyl alcohol-polyethylene glycol graft copolymer, has been applied in the formulation of tablets containing spray dried co-amorphous indomethacin-arginine by Petry et al. The applied coat provided a successful protection against humidity or heat, so that the obtained tablets were physically stable even when stored at humid conditions (RH/75\%) for approximately three months ${ }^{(104)}$. Likewise, tablets were formulated with CAM mixture of amlodipine besylate and atorvastatin calcium. The optimized formulations have proven their stability under tested conditions for three months. They also exhibited a significant increase in dissolution rates ${ }^{(105)}$.

\section{Conclusion}

Due to the increasing number of poorly aqueous soluble APIs, the CAM has emerged as a promising approach to overcome the limitations associated with the polymeric based amorphous dispersions (PASD) to improve solubility and dissolution of such APIs.

\section{Acknowledgment}

The authors are deeply grateful for the support from University of Mustansiriyah (www. uomustansiriyah.edu.iq), Baghdad-Iraq.

\section{References}

1. Broach JR, Thorner J. High-throughput screening for drug discovery. Nature 1996; 384(66D4):14-16.

2. Carnero A. High throughput screening in drug discovery. Clin Transl Oncol 2006; 8(7): 482490.

3. Amidon GL, Lennernas H, Shah VP, et al. A theoretical basis for a biopharmaceutic drug classification - the correlation of in-vitro drug product dissolution and in-vivo bioavailability. Pharm Res 1995; 12(3):413-420.

4. Di L, Fish PV, Mano T. Bridging solubility between drug discovery and development. Drug Disco Today 2012; 17(9-10): 486-495.

5. Sareen, S.; Mathew, G.; Joseph, L. Improvement in solubility of poor watersoluble drugs by solid dispersion. Int. J. Pharm. Investig. 2012; 2(1): 12-17.

6. Williams HD, Trevaskis NL, Charman SA, Shanker RM, Charman WN, Pouton CW, Porter CJ. Strategies to address low drug solubility in discovery and development. Pharmacol Rev 2013; 65(1): 315-499.

7. Kaushal, A, Gupta P, Bansal AK. Amorphous drug delivery systems: molecular aspects, design, and performance. Crit Rev Ther Drug Carrier Syst 2004; 21(3): 1-62.

8. Hancock BC, Zografi G. Characteristics and significance of the amorphous state in pharmaceutical systems. J Pharm Sci 1997; 86(1):1-12.

9. $\mathrm{Yu}$ L. Amorphous pharmaceutical solids: Preparation, characterization and stabilization. Adv. Drug Deliv Rev 2001; 48(1): 27-42.

10. Murdande SB, Pikal MJ, Shanker RM, Bogner RH. Solubility advantage of amorphous pharmaceuticals: I. A thermodynamic analysis. J Pharm Sci 2010; 99(3):1254-1264.

11. Moinuddin SM, Ruan S, Huang Y, Gao Q, Shi Q, Cai B, Cai T. Facile formation of coamorphous atenolol and hydrochlorothiazide mixtures via cryogenic-milling: Enhanced physical stability, dissolution and pharmacokinetic profile. Int J Pharm 2017; 532(1): 393-400.

12. Newman A, Reutzel-Edens SM, Zografi G. Coamorphous active pharmaceutical ingredientsmall molecule mixtures: Considerations in the choice of co-formers for enhancing dissolution and oral bioavailability. J Pharm Sci 2018; 107(1): 5-17.

13. Mc Ginity JW, Maincent $P$, Steinfink $H$. Crystallinity and dissolution rate of tolbutamide solid dispersions prepared by the melt method. J Pharm Sci 1984; 73(10): 1441-1444.

14. Liu C, Desai KGH. Liu C, Park HJ. Enhancement of dissolution rate of rofecoxib using solid dispersions with urea. Drug Dev Res 2004; 63(4): 181-89.

15. Chieng N, Aaltonen J, Saville D, Rades $T$. Physical characterization and stability of amorphous indomethacin and ranitidine hydrochloride binary systems prepared by mechanical activation. Eur J Pharm Biopharm 2009; 71(1): 47-54.

16. Yamamura S, Momose $\mathrm{Y}$, Takahashi $\mathrm{K}$, Nagatani S. Solid-state interaction between cimetidine and naproxen. Drug Stability 1996; 1(3): 173-178. 
17. Löbmann K, Jensen KT, Laitinen R, Rades $\mathrm{T}$, Strachan C, Grohganz H. Stabilized amorphous solid dispersions with small molecule excipients. In Amorphous Solid Dispersions; Springer 2014; 10(3): 613-636.

18. Alles $\varnothing \mathrm{M}$, Chieng N, Rehder S, Rantanen J, Rades T, Aaltonen J. Enhanced dissolution rate and synchronized release of drugs in binary systems through formulation: Amorphous naproxen-cimetidine mixtures prepared by mechanical activation. J Controll Release 2009; 136(1): 45-53.

19. Lenz E, Jensen KT, Blaabjerg LI, Knop K, Grohganz H, Löbmann K, Rades T, Kleinebudde P. Solid-state properties and dissolution behaviour of tablets containing coamorphous indomethacin-arginine. Eur J Pharm Biopharm 2015; 96: 44-52.

20. Löbmann K, Laitinen R, Grohganz H, Gordon KC, Strachan C, Rades T. Coamorphous drug systems: Enhanced physical stability and dissolution rate of indomethacin and naproxen. Mol Pharm 2011; 8(5):1919-1928.

21. Ford JL, Rubinstein MH. Preparation, properties and ageing of tablets prepared from the chlorpropamide-urea solid dispersion. Int J Pharm 1981; 8(4): 311-322

22. Suresh K, Mannava MKC, Nangia A. A novel curcumin-artemisinin co-amorphous solid: Physical properties and pharmacokinetic profile. RSC Adv 2014; 4(102): 58357-58361.

23. Chavan RB, Thipparaboina R, Kumar D, Shastri NR. Co- amorphous systems: A product development perspective. Int J Pharm 2016; 515(1-2): 403.

24. Maher EM, Ali AM, Salem HF, Abdelrahman AA. In vitro/in vivo evaluation of an optimized fast dissolving oral film containing olanzapine co-amorphous dispersion with selected carboxylic acids. Drug Deliv 2016; 23, 30883100.

25. Chavan RB, Thipparaboina R, Kumar D, Shastri NR. Evaluation of the inhibitory potential of HPMC, PVP and HPC polymers on nucleation and crystal growth. RSC Adv 2016;6, 77569-77576.

26. Cheng $\mathrm{H}$, Mao L, Zhang $\mathrm{S}$, Huixia LV .Impacts of polymeric additives on nucleation and crystal growth of indomethacin from supersaturated solutions AAPS Pharm SciTech 2019; 20: 193.

27. Mehta M, Kothari K, Ragoonanan V, Suryanarayanan R. Effect of water on molecular mobility and physical stability of amorphous pharmaceuticals. Mol. Pharmaceutics 2016; 13(4):1339-1346.

28. Shi Q, Moinuddin SM, Cain T. Advances in coamorphous drug delivery systems Acta Pharmaceutica Sinica B 2019;9(1):19-35.
29. Sato T, Taylor LS. Acceleration of the crystal growth rate of low molecular weight organic compounds in supercooled liquids in the presence of Polyhydroxybutyrate. Cryst Eng Comm 2017; 19: 80-87.

30. Grohganz H, Löbmann K, Priemel P, Jensen KT, Graeser K, Strachan C, Rades T. Amorphous drugs and dosage forms. J Drug Deliv Sci Technol 2013; 23: 403-408.

31. Grohganz H, Löbmann $K$, Priemel $P$, Jensen KT, Graeser K, Strachan C, Rades T. Amorphous drugs and dosage forms. J Drug Deliv Sci Technol 2013; 23: 403-408.

32. Karagianni A, Kachrimanis K, Nikolakakis I . Co-amorphous solid dispersions for solubility and absorption improvement of drugs: Composition, preparation, characterization and formulations for oral delivery. Pharmaceutics 2018; 10(3):98:1-26.

33. Laitinena $R$, Löbmanna $K$, Strachana CJ, Grohganzb H, Radesa T. Emerging trends in the stabilization of amorphous drugs. Int $\mathbf{J}$ Pharm 2013; 453(10):65- 79.

34. Dengale SJ, Ranjan OP, Hussen SS, Krishna B, Musmade PB, Shenoy GG, Bhat K. Preparation and characterization of co-amorphous Ritonavir-Indomethacin systems by solvent evaporation technique: Improved dissolution behavior and physical stability without evidence of intermolecular interactions. Eur J Pharm Sci 2014; 62: 57-64.

35. Yamamura S, Gotoh H, Sakamoto Y, Momose Y. Physicochemical properties of amorphous precipitates of cimetidine-indomethacin binary system. Eur J Pharm Biopharm 2000; 49(3): 259-265.

36. Yamamura S, Gotoh H, Sakamoto Y, Momose Y. Physicochemical properties of amorphous salt of cimetidine and diflunisal system. Int $\mathbf{J}$ Pharm 2002; 241(2): 213-221.

37. Löbmann K, Strachan C, Grohganz H, Rades T, Korhonen O, Laitinen R. Co-amorphous simvastatin and glipizide combinations show improved physical stability without evidence of intermolecular interactions. Eur J Pharm Biopharm 2012; 81(1): 159-169.

38. Ueda H, Kadota K, Imono M, Ito $T$, Kunita A, Tozuka Y. Co-amorphous formation induced by combination of tranilast and diphenhydramine hydrochloride. J Pharm Sci 2017; 106(1): 123128.

39. Gao Y, Liao J, Qi X, Zhang J. Co-amorphous repaglinide-saccharin with enhanced dissolution. Int J. Pharm. 2013; 450(1-2): 290295.

40. Shayanfar A, Ghavimi H, Hamishekar H, Jouyban A. Coamorphous atorvastatin calcium to improve its physicochemical and pharmacokinetic properties. J Pharm Sci 2013; 16(4): 577-587. 
41. $\mathrm{Hu} \mathrm{Y}$, Gniado $\mathrm{K}$, Erxleben $\mathrm{A}$, et al. Mechanochemical reaction of sulfathiazole with carboxylic acids: formation of a cocrystal, a salt, and co-amorphous solids. Cryst. Growth Des 2013; 14(2):803-813.

42. Lu Q, Zografi G. Phase behavior of binary and ternary amorphous mixtures containing indomethacin, citric acid, and PVP. Pharm Res 2014; 15(8):1202-1206.

43. Telang C, Mujumdar S, Mathew M. Improved physical stability of amorphous state through acid base interactions. J Pharm Sci 2009; 98(6):2149-2159.

44. Hussain MD, Saxena V, Brausch JF, et al. Ibuprofen--phospholipid solid dispersions: improved dissolution and gastric tolerance. Int J Pharm 2012; 422(1-2):290-294.

45. Ahuja N, Katare OP, Singh B. Studies on dissolution enhancement and mathematical modeling of drug release of a poorly watersoluble drug using water soluble carriers. Eur J Pharm Biopharm 2007; 65(1):26-38.

46. Grohganz H, Priemel PA, Löbmann K, Nielsen LH, Laitinen R, Mullertz A, Guy Van den Mooter GV ,et al. Refining stability and dissolution rate of amorphous drug formulations. Expert Opin Drug Deliv 2014; 11:977-989.

47. Masuda T, Yoshihashi Y, Yonemochi E, et al. Co-crystallization and amorphization induced by drug--excipient interaction improves the physical properties of acyclovir. Int $\mathrm{J}$ Pharm 2012; 422(1-2):160-169.

48. Hoppu P, Jouppila K, Rantanen J, et al. Characterisation of blends of paracetamol and citric acid. J Pharm Pharmacol 2007; 59(3):373381.

49. Löbmann K, Grohganz H, Laitinen R, Strachan C, Rades T. Amino acids as coamorphous stabilizers for poorly water soluble drugs - Part 1: Preparation, stability and dissolution enhancement. Eur J Pharm Biopharm 2013; 85(3): 873-881.

50. Löbmann K, Laitinen $R$, Strachan $C$, Rades $T$, Grohganz H. Amino acids as coamorphous stabilizers for poorly water-soluble drugs - Part 2: Molecular interactions. Eur J Pharm Biopharm 2013; 85(3): 882-888.

51. Jensen KT, Blaabjerg LI, Lenz E, Bohr A, Grohganz H, Kleinebudde $\mathrm{P}$, Rades $\mathrm{T}$. Löbmann K. Preparation and characterization of spray dried co-amorphous drug-amino acid salts. J Pharm Pharmacol 2016; 68(5): 615-624.

52. Vasconcelos $T$, Marques S, Das Neves J, Sarmento B. Amorphous solid dispersions: Rational selection of a manufacturing process. Adv Drug Deliv Rev 2016; 100:85-101.

53. Jensen KT, Löbmann K, Rades T, Grohganz H. Improving co-amorphous drug formulations by the addition of the highly water soluble amino acid, proline. Pharmaceutics 2014; 6(3): 416435.

54. Descamps M, Willart JF, Dudognon E, Caron V. Transformation of pharmaceutical compounds upon milling and comilling: the role of Tg. J Pharm Sci 2007; 96(5): 1398-1407.

55. Willart JF, Descamps M. Solid state amorphization of pharmaceuticals. Mol Pharmaceutics 2008; 5(6): 905-920.

56. Laitinen R, Priemel PA, Surwase S, Graeser K, Strachan CJ, Grohganz H, Rades T. Theoretical Considerations in Developing Amorphous Solid Dispersions, Amorphous Solid Dispersions. Springer 2014:35-90.

57. Skieneh JM, Sathisaran I, Dalvi SV, Rohani S. Co-amorphous form of curcumin-folic acid dihydrate with increased dissolution rate. Cryst Growth Des 2017; 17(12): 6273-6280.

58. Pang W, Lv J, Du S, Wang J, Wang J, Zeng Y. Preparation of curcumin-piperazine coamorphous phase and fluorescence spectroscopic and density functional theory simulation studies on the interaction with bovine serum albumin. Mol. Pharmaceutics 2017; 14(9): 3013-3024.

59. Descamps M, Willart JF. Perspectives on the amorphization/milling relationship in pharmaceutical materials. Adv Drug Deliv Rev 2016; 100: 51-66.

60. Feng T, Pinal R, Carvajal MT. Process induced disorder in crystalline materials: differentiating defective crystals from the amorphous form of griseofulvin. J Pharm Sci 2008; 97(8): 32073221.

61. Graeser KA, Strachan CJ, Patterson JE, Gordon KC, Rades T. Physicochemical properties and stability of two differently prepared amorphous forms of simvastatin. Cryst Growth Des 2008; 8(1): 128-135.

62. Ke P, Hasegawa S, Al-Obaidi H, Buckton G. Investigation of preparation methods on surface/bulk structural relaxation and glass fragility of amorphous solid dispersions. Int $\mathbf{J}$ Pharm 2012; 422(1-2):170-178.

63. Qian S, Heng W, Wei Y, Zhang J, Gao Y. Coamorphous lurasidone hydrochloridesaccharin with charge-assisted hydrogen bonding interaction shows improved physical stability and enhanced dissolution with $\mathrm{pH}$ independent solubility behavior. Cryst Growth Des 2015; 15(6):2920-2928.

64. Ojarinta R, Lerminiaux L, Laitinen R. Spray drying of poorly soluble drugs from aqueous arginine solution. Int J Pharm 2017; 532(1): 289-298.

65. Craye G, Löbmann K, Grohganz H, Rades, T, Laitinen R. Characterization of amorphous and co-amorphous simvastatin formulations prepared by spray drying. Molecules 2015; 20(12): 21532-21548. 
66. Zhu S, Gao H, Babu S, Garad S. Co-amorphous formation of high-dose zwitterionic compounds with amino acids to improve solubility and enable parenteral delivery. Mol Pharmaceutics 2018; 15(1): 97-107.

67. Hoppu P, Hietala S, Schantz S, Juppo AM. Rheology and molecular mobility of amorphous blends of citric acid and paracetamol. Eur J Pharm Biopharm 2009; 71(1): 55-63.

68. Löbmann K, Laitinen R, Grohganz H, Strachan C, Rades T, Gordon KC. A theoretical and spectroscopic study of co-amorphous naproxen and indomethacin. Int J Pharm 2013 b; 453(1): 80-87.

69. Wanapun D, Kestur US, Taylor LS, Simpson GJ. Single particle nonlinear optical imaging of trace crystallinity in an organic powder. Anal Chem 2011; 83(12): 4745-4751.

70. Hancock BC, Shamblin SL, Zografi G. Molecular mobility of amorphous pharmaceutical solids below their glass transition temperatures. Pharm Res 1995; 12(6):799-806.

71. Gordon M, Taylor JS. Ideal copolymers and the second-order transitions of synthetic rubbers. I. Non-crystalline copolymers, J Appl Chem. 1952; 2(9):493-500.

72. Shamblin SL, Huang EY, Zografi G. The effects of co-lyophilized polymeric additives on the glass transition temperature and crystallization of amorphous sucrose. J Therm Anal Calorim 1996; 47(5): 1567-1579.

73. Baird JA, Taylor LS. Evaluation of amorphous solid dispersion properties using thermal analysis techniques. Adv Drug Deliv Rev 2012; 64(5):396-421.

74. Russo GM, Sancho MI, Silva LMA, Baldoni HA, Venancio T, Javier E et al. Looking for the interactions between omeprazole and amoxicillin in a disordered phase. An experimental and theoretical study. Spectrochim Acta Part A 2016; 156: 70-77.

75. Han Y, Pan Y, Lv J, Guo W, Wang J. Powder grinding preparation of co-amorphous $\beta$ azelnidipine and maleic acid combination: Molecular interactions and physicochemical properties. Powder Technol 2015; 291:110120.

76. Pajula K, Taskinen M, Lehto VP, Ketolainen J, Korhonen O. Predicting the formation and stability of amorphous small molecule binary

88. Nair R, Nyamweya N, Gönen S, MartinezMiranda LJ, Hoag SW. Influence of various drugs on the glass transition temperature of poly (vinylpyrrolidone): a thermodynamic and spectroscopic investigation. Int J Pharm 2001; 225(1-2): 83-96.

89. Shamblin SL, Huang EY, Zografi G. The effects of co-lyophilized polymeric additives on the glass transition temperature and mixtures from computationally determined flory-huggins interaction parameter and phase diagram. Mol Pharm 2010; 7(3): 795-804.

77. Marsac J, Konno H, Taylor LS, A comparison of the physical stability of amorphous felodipine and nifedipine systems. Pharm Res 2006; 23(10): 2306-2316.

78. Liu $X$, Feng $X$, Williams RO, Zhan F. Characterization of amorphous solid dispersions. J Pharm Investig 2017; 48: 1-23.

79. $\mathrm{Yu}$ L. Amorphous pharmaceutical solids: preparation, characterization and stabilization. Adv Drug Deliv Rev 2001; 48(1): 27-42.

80. Thakral S, Terban MW, Thakral NK, Suryanarayanan R. Recent advances in the characterization of amorphous pharmaceuticals by X-ray diffractometry. Adv Drug Deliv Rev 2016; 100: 183-193.

81. Wei Y, Zhou S, Hao T, Zhang J, Gao Y, Qian S. Further enhanced dissolution and oral bioavailability of docetaxel by coamorphization with a natural P-gp inhibitor myricetin. Eur J Pharm Sci 2019; 129:21-30.

82. Debenedetti PG, Stillinger FH. Super cooled liquids and the glass transition. Nature 2001; 410(6825): 259-267.

83. Trasi NS, Byrn SR. Mechanically induced amorphization of drugs: a study of the thermal behavior of cryo-milled compounds. AAPS Pharm SciTech 2012; 13(3):772-7784.

84. Chattoraj S, Bhugra C, Telang C, Zhong L, Wang Z, Sun CC. Origin of two modes of nonisothermal crystallization of glasses produced by milling. Pharm Res 2012; 29(4):1020-1032.

85. Van Drooge DJ, Hinrichs WL, Visser MR, Frijlink HW. Characterization of the molecular distribution of drugs in glassy solid dispersions at the nano-meter scale, using differential scanning calorimetry and gravimetric water vapour sorption techniques. Int J Pharm 2006; 310(1-2):220-229.

86. Wang J, Chang R, Zhao Y, Zhang J , Zhang T, Fu Q et al. Coamorphous loratadine-citric acid system with enhanced physical stability and bioavailability. AAPS Pharm SciTech 2017; 18(7):2541-2550.

87. Martínez LM, Videa M, Sosa NG, Ramírez JH, Castro S. Long-term stability of new coamorphous drug binary systems: study of glass transitions as a function of composition and shelf time. Molecules 2016; 21(12): 1-13. crystallization of amorphous sucrose. J Therm Anal Calorim 1996; 47(5):1567-1579.

90. Shamblin SL. Taylor LS, Zografi G. Mixing behavior of co-lyophilized binary systems. J Pharm Sci 1998; 87(6):694-701.

91. Wu W, Löbmann K, Schnitzkewitz J, Knuhtsen A, Pedersen DS, Grohganz H et al. Aspartame as a co-former in co-amorphous systems. Int J Pharm 2018; 549(1-2):380-387. 
92. Renuka, Singh SK, Gulati M, Narang R. Stable amorphous binary systems of glipizide and atorvastatin powders with enhanced dissolution profiles: formulation and characterization. Pharm Dev Technol 2015; 22(1):13-25.

93. Jensen KT, Larsen FH, Cornett C, Löbmann K, Grohganz H, Rades T. Formation mechanism of coamorphous drug-amino acid mixtures. Mol Pharmaceutics 2015; 12(7): 2484-2492.

94. Fung MH, DeVault M, Kuwata KT, Suryanarayanan R. Drug-excipient interactions: Effect on molecular mobility and physical stability of ketoconazole-organic acid coamorphous systems. Mol Pharmaceutics 2018; 15(3):1052-1061.

95. Edinger M, Knopp MM, Kerdoncuff H, Rantanen J ,Rades T , Löbmann K. Quantification of microwave-induced amorphization of celecoxib in PVP tablets using transmission Raman spectroscopy. Eur J Pharm Sci 2018; 117: 62-67.

96. Qi S, McAuley WJ, Yang Z, Tipduangta P. Physical stabilization of low-molecular-weight amorphous drugs in the solid state: a material science approach. Ther Deliv 2014; 5(7): 817841.

97. Shergill M, Patel M, Khan S, Bashir A, McConville C. Development and characterization of sustained release solid dispersion oral tablets containing the poorly water soluble drug disulfiram. Int $\mathbf{J}$ Pharm 2016; 497(1-2): 3-11.

98. Arnfast L, Kamruzzaman M, Lobmann K, Aho J, Baldursdottir S, Rades T, Rantanen J. Melt extrusion of high-dose co-amorphous drug- drug combinations. Pharm Res 2017; 34(12): 2689-2697.

99. Willart JF, Carpentier L, Danede F, Descamps M. Solid-state vitrification of crystalline griseofulvin by mechanical milling. J Pharm Sci 2012; 101(4): 1570-1577.

100. Merisko-Liversidge E, Liversidge GG. Nanosizing for oral and parenteral drug delivery: a perspective on formulating poorlywater soluble compounds using wet media milling technology. Adv Drug Deliv Rev 2011; 63(6): 427-440.

101. Dawood NM, Abdal-hammid SN, Hussien AA. Formulation and characterization of lafutidine nanosuspension for oral drug delivery system. Int J App Pharm 2018; 10: 20-30.

102. Mishra J, Löbmann $K$, Grohganz $H$, Rades $T$. Influence of preparation technique on coamorphization of carvedilol with acidic amino acids. Int J Pharm 2018; 552(1-2):407-713.

103. Lipiäinen $T$, Peltoniemi $M$, Räikkönen $H$, Juppo A. Spray-dried amorphous isomalt and melibiose, two potential protein-stabilizing excipients. Int J Pharm 2016; 510(1): 311-332.

104. Petry I, Löbmann K, Grohganz H, Rades T, Leopold CS. Solid state properties and drug release behavior of co-amorphous indomethacin-arginine tablets coated with Kollicoat ${ }^{\circledR}$ Protect. Eur J Pharm Biopharm 2017; 119: 150-160.

105. Adahalli SB, Talluri $M$. formulation and evaluation of tablet prepared by coamorphous system containing anti-hypertensive and antihyperlipidemic drug. Int $\mathrm{J}$ Pharm Pharm Sci.2016; 8(9): 182-193. 